\title{
Synthetic and secretory processes of lactation
}

\section{By R. R. Dils, Department of Physiology \& Biochemistry, University of Reading,} Whiteknights, PO Box 228, Reading RG6 $2 A T$

The provision of a balanced diet before weaning is met by the ability of the lactating gland to assemble and secrete a unique combination of tissue-specific products. This review covers the mechanisms involved in the synthesis and secretion of milk fat, milk proteins and lactose during lactation. The hormonal control of lactation has been reviewed by Cowie et al. (1980).

\section{Milk fat synthesis and secretion}

A comparison of the gross composition of milk from different species shows that, of all major components, milk fat exhibits the greatest variation (Christie, 1983; Dils, 1984). By contrast, the proportions of different classes of lipids in milk fat is remarkably constant between species with triacylglycerols (triglycerides) predominating, the remaining components being associated with the milk-fat globule membrane (MFGM). This implies that the secretory cells of mammary alveoli of all species use the same mechanisms to produce a constant proportion of triacylglycerol to membrane lipid.

The proportions of individual fatty acids in the triacylglycerols of milk fat of different species show an extraordinary diversity (Christie, 1983; Dils, 1983). Ruminant milk fat is characterized by the presence of short-chain fatty acids, 4:0 and 6:0, which together represent $4.9-6.8 \%$ by weight of the total fatty acids. The milk triacylglycerols of many species, including ruminants, contain significant proportions of medium-chain fatty acids, 8:0-12:0, that are mammary-specific products. Ruminant milk fat, unlike that of non-ruminants, is characterized by the low proportion of long-chain polyunsaturated fatty acids due to rumen microbial hydrogenation of these dietary fatty acids.

\section{Origins of milk fatty acids}

Long-chain fatty acids (14:0 and longer). There are two major sources of these acids. The first is uptake by the mammary gland of chylomicrons and very-low-density lipoproteins, the fatty acid moieties of which are derived from intestinal absorption of dietary lipid and the mobilization of adipose tissue triacylglycerols. These lipoproteins are hydrolysed during uptake by lipoprotein lipase $(E C 3.1 .1 .34)$ in the capillaries of the gland, and the unesterified fatty acids and glycerol produced are re-esterified into triacylglycerol in the endoplasmic reticulum of mammary epithelial cells. There is also simultaneous uptake and release by the gland of unesterified fatty acids. For reviews, see Dils \& Parker (1982) and Annison (1983).

The second source is by fatty acid synthesis de novo within the cytosol of the mammary epithelial cell. This requires acetyl-CoA, both as 'primer' and as the precursor of malonyl-CoA needed for two-carbon elongation of the primer by fatty acid synthase ( $E C$ 2.3.1.85), together with NADPH for the reductive steps of the pathway. With nonruminants, glucose taken up by the gland is the major source of this acetyl-CoA and NADPH and it can supply some of the glycerol needed to form milk triacylglycerols. With ruminants, acetate and 3-hydroxybutyrate taken up by the gland are the predominant precursors for fatty acid synthesis de novo (see Dils \& Parker, 1982; Annison, 1983). In both cases, chain elongation continues until palmitate (16:0) is released from 
the fatty acid synthase by the long-chain acylthioesterase component (thioesterase I) of the synthase.

Medium-chain fatty acids $(8: 0-12: 0)$. The synthesis and release of these acids by fatty acid synthase requires premature termination of chain elongation. In the non-ruminant mammary gland this is brought about by the presence in the cytosol of the enzyme medium-chain acylthioesterase (thioesterase II) which terminates chain elongation at 8:0-12:0 acids by hydrolysing these acids from the synthase (see Dils \& Knudsen, 1980; Smith, 1980; Smith et al. 1983; Naggert et al. 1987).

There is a subtle difference in chain termination by ruminant mammary fatty acid synthase: the ability to synthesize medium-chain fatty acids as acyl-CoA esters is an inherent property of the synthase and the products can be esterified directly into triacylglycerols (Grunnet \& Knudsen, 1979a,b, 1983; Knudsen \& Grunnet 1982).

Short-chain fatty acids (4:0 and 6:0). In all species studied there is a significant uptake by the gland of 3-hydroxybutyrate which is then converted into butyryl-CoA (see Dils \& Parker, 1982). Butyryl-CoA, as well as hexanoyl-CoA, can also be synthesized de novo by mammary fatty acid synthase via the malonyl-CoA pathway (Hansen \& Knudsen, 1980). Since these short-chain acids are not present in non-ruminant milk triacylglycerols, they are presumably used as 'primers' to synthesize medium- and long-chain fatty acids de novo.

Ruminant mammary gland has the unique ability to esterify 4:0-CoA and 6:0-CoA into triacylglycerols (Hansen \& Knudsen, 1980). This might reflect a direct coupling, which does not occur with non-ruminants, of the synthesis of these esters with triacylglycerol formation by the acyltransferase(s) of the endoplasmic reticulum.

Desaturation, chain elongation and esterification of fatty acids into triacylglycerols. Moore \& Christie (1979) have reviewed the ability of ruminant mammary gland to desaturate stearate $(18: 0)$ to oleate $(18: 1)$ and palmitate $(16: 0)$ to palmitoleate $(16: 1)$, which can also occur in non-ruminant mammary tissue. Ruminant mammary gland does not appear to elongate palmitate whereas guinea-pig mammary gland synthesizes a high proportion of stearate (Strong \& Dils, 1972). The sn-glycerol-3-phosphate pathway of esterification of fatty acyl-CoA esters is the principal route of triacylglycerol synthesis by ruminant mammary endoplasmic reticulum acyltransferases, as it probably is with non-ruminants (see Moore \& Christie, 1979). Hansen et al. (1986) have shown that the monoacylglycerol pathway is unimportant in lactating goat mammary gland.

\section{Secretion of milk fat}

Fatty acids taken up by the mammary gland are rapidly incorporated into fat droplets in the secretory cell (Daudet et al. 1981). This implies that triacylglycerols can be added to existing intracellular lipid droplets in the course of their transport to the apical membrane. Keenan et al. (1983) have provided evidence that intracellular fat droplets originate from triacylglycerol-containing vesicles ('lipovesicles') which bleb from regions of the endoplasmic reticulum. Growth occurs by continued fusion of lipovesicles with each other and with larger fat droplets during transit to the apical membrane. There is no direct evidence (see Nickerson \& Keenan, 1979; Henderson \& Peaker, 1980; Keenan et al. 1983; Mather \& Keenan, 1983) that microtubules or microfilaments are involved in the intracellular movement of fat droplets.

Strong evidence that the MFGM is largely derived from the apical membrane comes from the finding that butyrophin, which tenaciously binds phospholipids, is only found in the apical membrane and the MFGM. This glycoprotein may be involved in attachment of the membrane of intracellular lipid droplets to the cytoplasmic surface of the apical membrane, leading to the vectorial discharge of milk-fat droplets (Franke et al. 1981; 
Heid et al. 1983; Keenan et al. 1983). Evidence that the lumen surface of the apical membrane becomes the exposed surface of the MFGM is provided by the wide range of glycoproteins found on the surface of the MFGM (Horisberger et al. 1977; Keenan et al. 1983).

\section{Synthesis of milk proteins}

Provision of amino acids. The uptake, transport and metabolism of amino acids required for the synthesis of milk proteins has been reviewed by Mepham et al. (1982) and summarized by Mepham (1987).

Transcription of milk-protein genes. In view of the extensive literature on this topic, the hormonal induction of specific mRNAs for milk protein synthesis is inevitably outside the scope of this article. The regulation by prolactin and steroids of casein mRNA synthesis and turnover during pregnancy and lactation has been reviewed by Mepham et al. (1982) and Mercier \& Gaye (1983). Rosen et al. (1986) have summarized recent work using molecular genetics to elucidate regulatory sequences of DNA involved in the hormonal control of the expression of the casein gene.

Translation of milk-protein $m R N A s$. The lactating mammary cell is characterized by a high proportion of ribosomes associated with the membranes of the endoplasmic reticulum. This arrangement enables the 'signal' sequence of mRNAs for milk proteins destined for secretion to be translated on membrane-bound ribosomes into a 'signal' peptide of fifteen to twenty-one amino acids at the amino-terminal end of the growing polypeptide chain. This peptide recognizes putative receptors and initiates the binding of functioning ribosomes to the endoplasmic reticulum membrane. Transfer of the growing polypeptide chains occurs, possibly through transient pores, with concomitant removal of the signal peptide by peptidases located on the lumen side of the endoplasmic membrane.

Analysis of the signal peptides of the six main ovine milk proteins (for details, see Mepham et al. 1982) reveals that $\alpha_{\mathrm{s} 1^{-}}, \alpha_{\mathrm{s} 2}-$, and $\beta$-caseins have $70 \%$ homology, but the signal peptides of the other ovine milk proteins differ markedly. Nevertheless, in all cases they fit the overall structural pattern common to all signal peptides sequenced so far, having a common hydrophobic character and common conformation. Comparison between species shows that the signal peptides of $\alpha_{\mathrm{s} 2}-$ and $\beta$-caseins and $\beta$-lactoglobulins are remarkably conserved with at least $85 \%$ homology, whereas that of $\alpha$-lactalbumin has evolved rather rapidly (for further details, see Mercier \& Gaye, 1983; Mepham et al. 1982).

Co-translational modification of presecretory milk proteins: $N$-glycosylation. Many proteins synthesized by mammary cells are glycosylated, including those synthesized to replenish membrane proteins lost as the MFGM. The $\mathrm{N}$-glycosylation of proteins probably proceeds in the endoplasmic reticulum co-translationally on nascent polypeptide chains (Hanover \& Lennarz, 1980) and involves the enzymic transfer of dolichollinked oligosaccharides to asparaginyl residues (Parodi \& Leloir, 1979). Though $\alpha$-lactalbumin is not a glycoprotein in some species, there is evidence that rat and rabbit $\alpha$-lactalbumin are glycosylated as described previously (Lingappa et al. 1978; Gaye et al. 1982). The large oligosaccharide chain is probably shortened as the glycoprotein moves through the endoplasmic reticulum and the Golgi (Gibson et al. 1980).

Post-translational modification of pre-secretory milk proteins: O-glycosylation and phosphorylation. K-Casein, the major glycoprotein synthesized by the mammary gland, contains several oligosaccharide chains each linked to threonyl residues (Mercier \& Gaye, 1983). It is presumed to be glycosylated in the Golgi by sequential transfer of monosaccharides from nucleotide sugars. 
The phosphorylation of caseins is probably a stepwise process involving the enzymic recognition of the amino acid triplet Ser/Thr-X-acidic residue (Mercier, 1981). Phosphorylation appears to take place on transfer of the completed polypeptide chain to the Golgi. The rather 'open' structure of the casein molecule is thought to allow phosphorylation sites to be accessible to casein kinases (Mercier \& Gaye, 1983). The tighter folding of the chains of $\alpha$-lactalbumin and $\beta$-lactoglobulin may explain why they are not phosphorylated, despite having potential phosphorylation sites. O'Hara et al. (1986) and Wilde \& Knight (1986) have used mammary explants to show that there is minimal degradation of post-translationally completed casein when its synthesis and secretion is at a maximum. Whether this affects net casein production in vivo is not known.

Synthesis of 'new' milk proteins. A closely related family of proteins (whey acidic proteins) have been identified in mouse and rat milk (Piletz et al. 1981) and their mRNAs isolated (Henninghausen et al. 1982), though their role in lactation is unknown. Very recently, the iron-binding protein, transferrin, has been identified as a major protein synthesized by mammary epithelial cells of the rat and rabbit (Lee et al. 1987). It has an unusual pattern of synthesis, i.e., increasing during pregnancy and decreasing during lactation, and being relatively insensitive to the effects of lactogenic hormones. A possible role for transferrin in mammary development and differentiation has been suggested by Lee et al. (1987).

\section{Synthesis of lactose}

Experiments with perfused ruminant mammary gland show that virtually all the glucose moiety of lactose is derived from blood glucose, whereas part of the galactose moiety is derived from acetate and glycerol-C (Dils \& Parker, 1982).

The sequence of enzyme-catalysed reactions in the cytosol of mammary epithelial cells leading to the formation of UDP-galactose has been reviewed by Kuhn (1983). The final step in the biosynthesis of lactose from UDP-galactose and glucose is catalysed by galactosyl transferase (EC 2.4.1.151) which is embedded in the inner surface of Golgi membranes. This enzyme, which is involved in glycoprotein synthesis in tissues, has a poor affinity for glucose $\left(K_{m}\right.$ of about $\left.1 \mathrm{M}\right)$. The specificity of the enzyme is profoundly modified by transient association with $\alpha$-lactalbumin transported from the endoplasmic reticulum through the Golgi en route to the apical membrane. This 'specific protein' creates a binding site for glucose so that the affinity of the transferase for glucose increases about 500 -fold $\left(K_{m}\right.$ about $2 \mathrm{~mm}$ ). This allows the synthesis of lactose in the Golgi to occur at the physiological concentrations of glucose found in the mammary epithelial cell.

The uridine nucleotide cycle proposed by Kuhn (1983) ensures the destruction of the UDP released in the Golgi lumen as lactose is formed. This removes what would otherwise be a powerful inhibitor of lactose synthesis. At the same time, lactose is permitted to accumulate to high concentrations within the Golgi lumen, whilst avoiding osmotically-undesirable concentrations in the cytosol (Kuhn \& White, 1977). The ability of Golgi membranes and secretory vesicles of mammary epithelial cells to retain lactose is crucial to the role of lactose in controlling the inflow of water, and hence the osmolarity of milk, since water accounts for over $80 \%$ of milk volume in the majority of species.

$\alpha$-Lactalbumin can no longer be regarded as unique. A homologous protein has been isolated from the reproductive tract fluids of the male rat (Hamilton, 1981) and Qasba et al. (1983) have suggested that its function in rat epididymis may be to 'specify' the transfer of galactose from UDP-galactose to myo-inositol linked to membrane-bound glycoproteins. 


\section{Secretion of milk proteins and lactose}

Milk proteins and lactose destined for secretion are channelled through a series of membrane compartments, i.e., the endoplasmic reticulum (in the case of milk proteins), the Golgi, and the secretory vesicles which ultimately fuse with the apical membrane and release the sequestered proteins and lactose into the lumen. It has been suggested that the cis-cisternae of the Golgi are related to the endoplasmic reticulum. Only vesicles destined to reach the apical membrane are transferred from the cis- to the trans-cisternae of the Golgi, whilst the remainder are recycled back to the endoplasmic reticulum (Mepham et al. 1982). This model of vesicular secretion implies that newly made proteins and lactose are secreted in a 'first-synthesized-first-secreted' manner (Kuhn, 1983). The work of Shappell et al. (1986) provides important evidence that there is a single population of secretory vesicles containing both casein and $\alpha$-lactalbumin.

The orientation and distribution of microtubules in the lactating mammary cell support the view that they are involved in the movement of secretory vesicles to the apical membrane; the association of microtubules and microfilaments with secretory vesicles and the apical membrane is clearly seen by electron microscopy (Nickerson \& Keenan, 1979). The growth of secretory vesicles is assumed to be a consequence of lactose synthesis which generates an osmotic gradient and forces the vesicles to swell as water flows in to maintain osmotic equilibrium. As secretory vesicles fuse, the additional membrane allows further influx of water because proportionately less membrane per unit volume is required for larger vesicles (Mather \& Keenan, 1983).

Exocytosis involves the local fusion of membranes of secretory vesicles with the cytoplasmic face of the apical membrane, the re-organization of the fused membrane and the discharge of synthesized proteins and lactose into the lumen. Two aspects of this process are of particular interest. First, secretory vesicles are characterized by a 'coat structure' on their surface. As they approach the apical membrane, a series of regularly shaped bridges form with the cytoplasmic face of the apical membrane due, presumably, to the presence of specific receptors on the latter (see Mather \& Keenan, 1983). Second, a sequence has been proposed ('compound exocytosis') in which secretory vesicles assemble into a chain-like structure at the apical membrane. The vesicles then link, fuse and release their products into the lumen. The structure then 'collapses' and fuses with the apical membrane (Dylewski \& Keenan, 1983; Keenan \& Dylewski, 1985).

The fate of the additional membrane continuously added to the apical surface during exocytosis is unknown. Mather \& Keenan (1983) have calculated that twenty-five to 200 times more membrane is added to the surface than is needed for the secretion of the MFGM. They concluded that a large proportion of this additional membrane is retrieved and conserved by the return of vesicles to the endoplasmic reticulum and the transcisternae of Golgi for re-use, or possibly degradation by lysosomes. For each epithelial cell an area of membrane equivalent to its entire apical surface needs to be replaced every 8-10 h to account for the formation of the MFGM (Franke et al. 1976). Since this is only a very small proportion of the amount of vesicular membrane added to the apical surface during this period, the 'flow' of membranes in mammary secretory cells that are secreting over three times their own volume in the form of milk daily (Mather \& Keenan, 1983) must be prodigious. 


\section{REFERENCES}

Annison, E. F. (1983). In Biochemistry of Lactation, F: 339-436 [T. B. Mepham, editor]. Amsterdam: Elsevier.

Christie, W. W. (1983). In Developments in Dairy Chemistry-2. Lipids, pp. 1-35 [P. F. Fox, editor]. London: Applied Science Publishers.

Cowie, A. T., Forsyth, I. A. \& Hart, I. C. (1980). Hormonal Control of Lactation. Berlin: Springer-Verlag.

Daudet, F., Augeron, C. \& Ollivier-Bousquet, M. (1981). European Journal of Biology 24, 197-202.

Dils, R. R. (1983). In Biochemistry of Lactation, pp. 141-157 [T. B. Mepham, editor]. Amsterdam: Elsevier.

Dils, R. R. (1984). Journal of Dairy Science 69, 904-910.

Dils, R. R. \& Knudsen, J. (1980). Biochemical Society Transactions 8, 292-294.

Dils, R. R. \& Parker, D. S. (1982). In Biochemical Development of the Fetus and Neonate, pp. 573-590 [C. T. Jones, editor]. Amsterdam: Elsevier Biomedical Press.

Dylewski, D. P. \& Keenan, T. W. (1983). European Journal of Cell Biology 31, 114-124.

Franke, W. W., Heid, H. W., Grund, C., Winter, S., Freudenstein, C., Schmidt, E., Jarasch, E.-D. \& Keenan, T. W. (1981). Journal of Cell Biology 89, 485-494.

Franke, W. W., Lüder, M. R., Kartenbeck, J., Zerban, H. \& Keenan, T. W. (1976). Journal of Cell Biology 69, 174-195.

Gaye, P., Hue, D., Raymond, M. N., Hazé, G. \& Mercier, J. C. (1982). Biochimie 64, 173-184.

Gibson, R., Kornfeld, S. \& Schlesinger, S. (1980). Trends in Biochemical Sciences 5, $290-293$.

Grunnet, I. \& Knudsen, J. (1979a). European Journal of Biochemistry 95, 497-502.

Grunnet, I. \& Knudsen, J. (1979b). European Journal of Biochemistry 95, 503-507.

Grunnet, I. \& Knudsen, J. (1983). Biochemical Journal 209, 215-222.

Hamilton, D. W. (1981). Biology of Reproduction 25, 385-392.

Hanover, J. A. \& Lennarz, W. J. (1980). Journal of Biological Chemistry 255, 3600-3604.

Hansen, H. O., Jensen, S. S. \& Knudsen, J. (1986). Biochemical Journal 238, 173-176.

Hansen, J. K. \& Knudsen, J. (1980). Biochemical Journal 186, $287-294$.

Heid, H. W., Winter, S., Bruder, G., Keenan, T. W. \& Jarasch, E.-D. (1983). Biochimica et Biophysica Acta 728, 228-238.

Henderson, A. J. \& Peaker, M. (1980). Quarterly Journal of Experimental Physiology 65, 367-368.

Henninghausen, L. G., Sippel, A. E., Hobbs, A. A. \& Rosen, J. M. (1982). Nucleic Acids Research 10, 3733-3744.

Horisberger, M., Rosset, J. \& Vonlanthen, M. (1977). Experimental Cell Research 109, 361-369.

Keenan, T. W. \& Dylewski, D. P. (1985). Journal of Dairy Science 68, 1025-1040.

Keenan, T. W., Dylewski, D. P., Woodford, T. A. \& Ford, R. H. (1983). In Developments in Dairy Chemistry-2. Lipids, pp. 83-118 [P. F. Fox, editor]. London: Applied Science Publishers.

Knudsen, J. \& Grunnet, I. (1982). Biochemical Journal 202, 139-143.

Kuhn, N. J. (1983). In Biochemistry of Lactation, pp. 159-176 [T. B. Mepham, editor]. Amsterdam: Elsevier.

Kuhn, N. J. \& White, A. (1977). Biochemical Journal 168, 423-433.

Lee, E. Y.-H., Barcellos-Hoff, M. H., Chen, L.-H., Parry, G. \& Bissell, M. J. (1987). In Vitro and Cellular Development 23, 221-226.

Lingappa, V. R., Lingappa, J. R., Prasad, R., Ebner, K. \& Blobel, G. (1978). Proceedings of the National Academy of Sciences, USA 75, 2338-2342.

Mather, I. H. \& Keenan, T. W. (1983). In Biochemistry of Lactation, pp. 231-283 [T. B. Mepham, editor]. Amsterdam: Elsevier.

Mepham, T. B. (1987). Physiology of Lactation. Milton Keynes: Open University Press.

Mepham, T. B., Gaye, P. \& Mercier, J.-C. (1982). In Developments in Dairy Chemistry-1. Proteins, pp. 115-156 [P. F. Fox, editor]. London: Applied Science Publishers.

Mercier, J.-C. (1981). Biochimie 63, 1-17.

Mercier, J.-C. \& Gaye, P. (1983). In Biochemistry of Lactation, pp. 177-227 [T. B. Mepham, editor]. Amsterdam: Elsevier.

Moore, J. H. \& Christie, W. W. (1979). Progress in Lipid Research 17, 347-395.

Naggert, J., Williams, B., Cashman, D. P. \& Smith, S. (1987). Biochemical Journal 243, 597-601.

Nickerson, S. C. \& Keenan, T. W. (1979). Cell Tissue Research 202, 303-312.

O'Hara, M., Kirwin, P., Razooki-Hasan, H., Wilde, C., White, D. A. \& Mayer, R. J. (1986). Biochimica et Biophysica Acta 889, 49-58.

Parodi, A. J. \& Leloir, L. F. (1979). Biochimica et Biophysica Acta 559, 1-37.

Piletz, J. E., Heinlen, M. \& Ganchow, R. E. (1981). Journal of Biological Chemistry 256, 11509-11516. 
Qasba, P. K., Hewlett, I. K. \& Byers, S. (1983). Biochemical and Biophysical Research Communications 117, 306-312.

Rosen, J. M., Jones, W. K., Rodgers, J. R., Compton, J. G., Bisbee, C. A., David-Inouye, Y. \& Yu-Lee, L.-Y. (1986). Annals of the New York Academy of Sciences 464, 87-99.

Shappell, N. W., Dylewski, D. P. \& Keenan, T. W. (1986). Protoplasma 135, 112-118.

Smith, S. (1980). Journal of Dairy Science 63, 337-352.

Smith, S., Pasco, D. \& Nandi, S. (1983). Biochemical Journal 212, 155-159.

Strong, C. R. \& Dils, R. R. (1972). Comparative Biochemistry and Physiology 40B, 643-652.

Wilde, C. J. \& Knight, C. H. (1986). Comparative Biochemistry and Physiology 84B, 197-201. 